\title{
Characterization of Fine Particles of Different Iron Oxides Formed in Aqueous Media*
}

\author{
Shigeru Suzuki, ${ }^{\dagger}$ Shinya Suzuki, Sang-Koo Kwon, Kiyoshi Kanie, Atsushi Muramatsu, and Yoshio Waseda \\ Institute of Multidisciplinary Research for Advanced Materials, \\ Tohoku University, Katahira, Aoba-ku, Sendai, 980-8577, Japan \\ Masaki Sakurai and Eiichiro Matsubara \\ Institute for Materials Research, Tohoku University, Katahira, Aoba-ku, Sendai, 980-8577, Japan \\ Makoto Okui and Sei Fukushima \\ National Institute for Materials Science, Mikazuki-cho, Hyogo 679-5148, Japan \\ (Received 12 December 2005; Accepted 15 February 2006; Published 12 April 2006)
}

\begin{abstract}
Small-angle X-ray scattering (SAXS) measurements using synchrotron radiation and transmission electron microscopy (TEM) observation have been carried out for characterizing fine particles of ferric oxides including hydroxides and oxyhydroxides. A compact chamber was designed for SAXS measurements at BL15XU of SPring-8, Japan. SAXS profiles of reference particles of ferric oxyhydroxides, namely, $\alpha$-FeOOH (goethite), $\beta$-FeOOH (akaganetite), and $\gamma-\mathrm{FeOOH}$ (lepidocrocite), obtained using the measurement system were compared with their morphologies observed by TEM. SAXS profiles of fine particles of ferric oxides, that were converted from condensed $\mathrm{Fe}(\mathrm{OH})_{3}$ gel to $\beta$-FeOOH and $\alpha-\mathrm{Fe}_{2} \mathrm{O}_{3}$ by aging, were also measured. While TEM observation provided information on the characteristic microstructure of well-crystallized fine particles of ferric oxides in a selected area of a sample, information regarding fine particles including poorly crystallized ferric oxides in the entire sample was obtained by SAXS measurements. The SAXS and TEM results indicated that the addition of foreign anions of sulfate or silicate to the gel delayed the conversion processes of the gel to $\beta$-FeOOH and $\alpha-\mathrm{Fe}_{2} \mathrm{O}_{3}$. A combination of SAXS measurement with TEM observation and X-ray diffraction measurement is shown to be effective in the characterization of fine particles of different iron oxides, which are formed by aging in aqueous media. [DOI: 10.1380/ejssnt.2006.352]

Keywords: X-ray Scattering; Iron Oxide; Surface-liquid interfaces
\end{abstract}

\section{INTRODUCTION}

Fine particles of iron oxides, including ferric hydroxides and oxyhydroxides, are used as support materials of catalysts, precursors of magnetic materials, and so on, which are synthesized via aqueous media $[1,2]$. The particles of iron oxides are very fine since they are formed through precipitation of ferric and/or ferrous ions dissolved in water. Thus, it is difficult to control the structure and morphology of particles of iron oxides because their formation mechanism in aqueous media is still unclear [2, 3]. Nevertheless, a number of studies have been conducted on the formation of iron oxides in aqueous media [4-9], focusing on the control of their morphologies. Although conventional analytical methods, such as X-ray diffraction (XRD), transmission electron microscopy (TEM), and Fourier transform infrared spectroscopy (FT-IR), are utilized for characterizing the particles, information obtained by these methods are not necessarily sufficient to characterize the instable morphology of mixed iron oxides.

The small-angle X-ray scattering (SAXS) method is one of the effective methods for obtaining morphological information on very fine particles or precipitates [10-14]. The local structure around specific atoms in nanoscale particles of a multi-component system is analyzed by combining the SAXS method with anomalous X-ray scattering

*This paper was presented at 5th International Symposium on Atomic Level Characterizations for New Materials and Devices (ALC05), Hawaii, USA, 4-9 December, 2005.

†Corresponding author: ssuzuki@tagen.tohoku.ac.jp in which synchrotron radiation is used $[15,16]$. As the SAXS method using a conventional X-ray source has also been carried out for analyzing fine particles of iron oxides prepared in aqueous media [17], this method may be useful for characterizing complicated fine particles.

Thus, the objective of this work is to establish a system for SAXS measurements in a beamline of synchrotron, and to use it to the characterization of fine particles of iron oxides prepared in aqueous media under different conditions. The system can be applied to anomalous scattering measurements using synchrotron radiation of a wide energy range, although only simple SAXS measurements were performed in this work. The SAXS measurement system was utilized for characterizing three reference particles of ferric oxyhydroxides - namely, $\alpha$-FeOOH, $\beta$-FeOOH, and $\gamma-\mathrm{FeOOH}-$ and fine particles of ferric oxides that were prepared by conversion from condensed $\mathrm{Fe}(\mathrm{OH})_{3}$ gel to $\beta$-FeOOH and $\alpha-\mathrm{Fe}_{2} \mathrm{O}_{3}$. SAXS profiles of these samples were compared with results by TEM observation. As sulfate ions and silicate ions are known to influence conversion processes of the $\mathrm{Fe}(\mathrm{OH})_{3}$ gel during aging [5-7], the particles of ferric oxides with these anions were also measured using this system.

\section{EXPERIMENTAL}

\section{A. Sample preparation}

The reference samples used were fine particles of $\alpha$ $\mathrm{FeOOH}$ (goethite), $\beta$-FeOOH (akaganeite), and $\gamma$-FeOOH (lepdocrocite), which are commercially available or pre- 
(a)

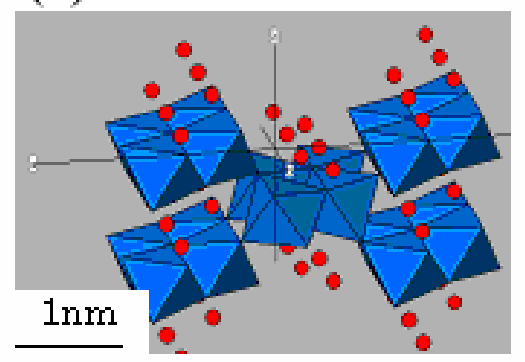

(b)

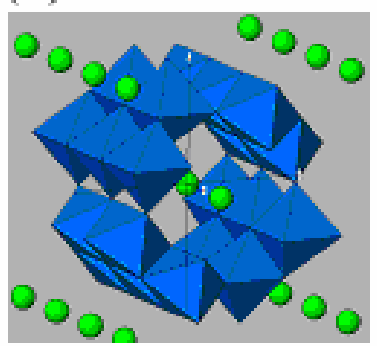

(c)

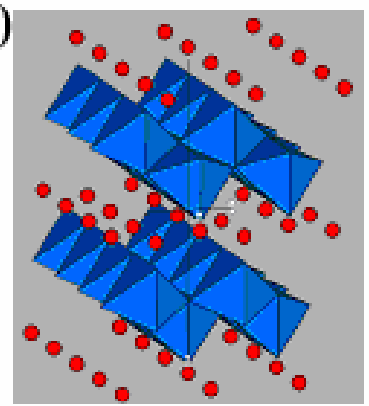

FIG. 1: The atomic-level structure of three ferric oxyhydroxides: (a) $\alpha-\mathrm{FeOOH}$, (b) $\beta$-FeOOH, and (c) $\gamma$-FeOOH.

pared in a laboratory $[3,4]$. The ideal crystallographic structures of $\alpha-\mathrm{FeOOH}, \beta-\mathrm{FeOOH}$, and $\gamma-\mathrm{FeOOH}$ are shown in Fig.1. Their structures are described using the $\mathrm{FeO}_{6}$ octahedral units, and hydrogen is denoted by small circles in the $\alpha-\mathrm{FeOOH}$ and $\gamma-\mathrm{FeOOH}$ structures. Chlorine is denoted by medium-sized circles in the $\beta$-FeOOH structure in which the position of hydrogen has not been fully determined yet. These ferric oxyhydroxides are precipitated from ferric and/or ferrous ions dissolved in aqueous media via olation and oxolation $[1,2]$. For stable crystallographic planes in these ferric oxyhydroxides, their fine particles exhibit characteristic morphologies. The basic morphologies of $\alpha-\mathrm{FeOOH}$ and $\beta$-FeOOH are generally acicular or rod-shaped, while the morphology of $\gamma$ $\mathrm{FeOOH}$ is lath-like or tabular [1]. The incorporation of foreign cations and anions in the particles are likely to distort their structures and morphologies at the atomic scale $[18,19]$.

Fine particles of ferric oxides converted from condensed $\mathrm{Fe}(\mathrm{OH})_{3}$ gel were also obtained. This gel was made from reagent-grade ferric chloride hexahydrate $\left(\mathrm{FeCl}_{3} \cdot 6 \mathrm{H}_{2} \mathrm{O}\right)$ and sodium hydroxide aqueous solution, and it is known to is converted to $\beta$-FeOOH and $\alpha-\mathrm{Fe}_{2} \mathrm{O}_{3}$ particles by aging at $373 \mathrm{~K}[3,4]$. The preparation method of particles of ferric oxides $-\mathrm{Fe}(\mathrm{OH})_{3}$ gel, $\beta$-FeOOH, and $\alpha-\mathrm{Fe}_{2} \mathrm{O}_{3}-$ was described in previous reports $[3,4]$. In order to investigate the influence of sulfate ions and silicate ions on the conversion of $\mathrm{Fe}(\mathrm{OH})_{3}$ gel, condensed $\mathrm{Fe}(\mathrm{OH})_{3}$ gel containing sulfate ions $\left(30 \mathrm{~mol} \% \mathrm{SO}_{4}^{2}\right)$ or silicate ions (5 $\left.\mathrm{mol} \% \mathrm{SiO}_{4}^{4}\right)$ were also prepared $[5-7]$.

\section{B. Measurements}

A vacuum chamber for SAXS measurements that was designed for BL15XU, SPring-8 and attached to its diffractometer is shown in Fig. 2. In SAXS measurements, a synchrotron radiation beam with a selected energy enters the vacuum chamber through a window of a Kapton film and is sharpened by a $1 \mathrm{~mm} \times 1 \mathrm{~mm}$ slit positioned just before the sample. Intensities of the beam transmitted through the sample were measured using a counter that was outside the chamber and positioned about $600 \mathrm{~mm}$ away from the sample. SAXS profiles were measured by scanning the counter in the $2 \theta$ mode. The beam energy used for SAXS measurements in this work was $6.92 \mathrm{eV}$, and thereby, the emission of fluorescent $\mathrm{X}$ -

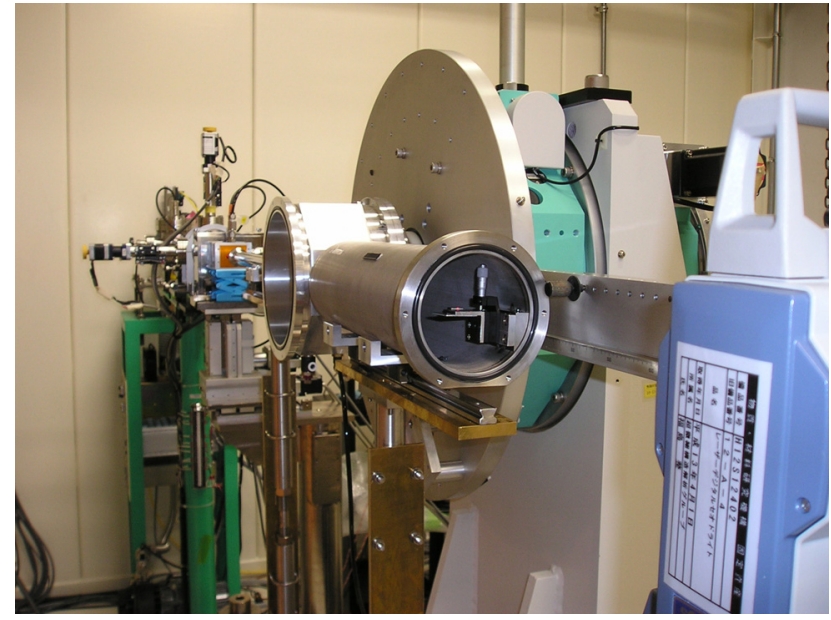

FIG. 2: Chamber for SAXS measurements attached to a diffractometer of BL15XU, SPring-8.

rays from samples was avoided. SAXS profiles were measured in the range of the scattering vector $Q$ between 0.2 and $3.0 \mathrm{~nm}^{-1}$. The intensities of scattered X-ray for the sample were normalized by its X-ray absorption coefficient, which was obtained by measuring the intensities of the direct incident X-ray and the X-ray absorbed by the sample.

Along with SAXS measurements, transmission electron microscopy (TEM) was used for observing the microstructures of fine particles of iron oxides using JEOL JEM1200EX II with an acceleration voltage of $120 \mathrm{kV}$. Characteristic features of the microstructures of the fine particles were compared with SAXS profiles. In addition, the crystallographic structures of the fine particles were partially identified by X-ray diffraction equipment using $\mathrm{Cu}$ $\mathrm{K}_{\alpha}$ radiation.

\section{RESULTS AND DISCUSSION}

\section{A. Reference particles of ferric oxyhydroxides}

TEM micrographs of the reference particles of three ferric oxyhydroxides $-\alpha$-FeOOH, $\beta$-FeOOH, and $\gamma$ FeOOH - used in this work are shown in Figs. 3(a), (b), and (c), respectively. The morphologies of the particles 


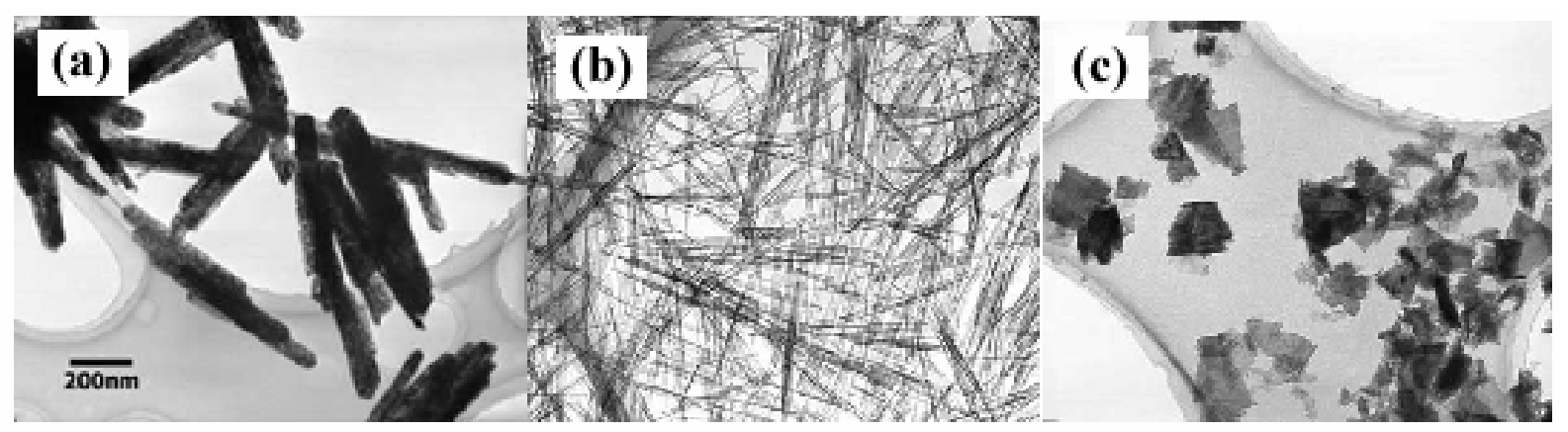

FIG. 3: Transmission electron micrographs of particles of three ferric oxyhydroxides: (a) $\alpha$-FeOOH, (b) $\beta$-FeOOH, and (c) $\gamma$-FeOOH.

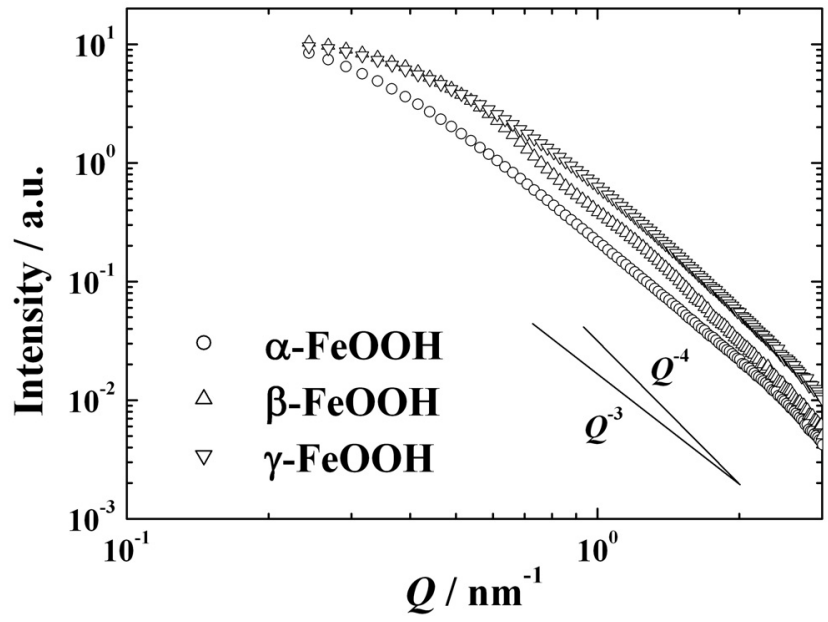

FIG. 4: SAXS profiles of reference particles of three ferric oxyhydroxides: $\alpha$-FeOOH, $\beta$-FeOOH, and $\gamma$-FeOOH.

of $\alpha$-FeOOH and $\beta$-FeOOH were acicular, and the diameters of the particles of $\alpha-\mathrm{FeOOH}$ and $\beta$-FeOOH were about $50 \mathrm{~nm}$ and $5 \mathrm{~nm}$, respectively. On the other hand, the shape of the particles of $\gamma-\mathrm{FeOOH}$ was tabular and their thickness was a few nanometers. These results are in agreement with the morphologies expected from their atomic-level structures shown in Fig. 1. However, the particles of these ferric oxyhydroxides appear to be not fully mono-dispersive and perfect.

Figure 4 shows $\ln (I)-\ln (Q)$ plots of SAXS profiles for the particles of $\alpha$-FeOOH, $\beta$-FeOOH, and $\gamma$-FeOOH. The SAXS profiles are characteristic of the morphologies and microstructures of the samples, which may correspond to the micrographs shown in Fig. 3. For instance, a slight oscillation observed at the scattering vector of about 0.8 $\mathrm{nm}^{-1}$ in the profile for the $\beta$-FeOOH particles is considered to be due to the fact that the shape of the acicular $\beta$-FeOOH particles is relatively homogeneous or nearly mono-dispersive as shown in Fig. 3(b). The slope in the large scattering vector range of the plots of these particles, which gives a fractal dimension of the surface, is between minus three and minus four. This result indicates that the surfaces of the particles are somewhat rough since the slope is nearly minus four in particles with a smooth surface $[10]$.
The effective diameters of rod-shaped or acicular particles are sometimes estimated using a cross-section plot $\left(Q \times \ln (I)-Q^{2}\right)$ of SAXS profiles [10]. Cross-section plots of SAXS profiles for acicular particles of $\alpha$-FeOOH and $\beta$-FeOOH are shown in Fig. $5(\mathrm{a})$. The slopes, $R_{c}^{2}$, in the cross-section plots for $\alpha$-FeOOH and $\beta$-FeOOH are related to the diameter $r$, which is given by $r=\sqrt{2} R_{c}$. Thus, the diameters of the particles of $\alpha$-FeOOH and $\beta$ FeOOH are estimated to be $4.0 \mathrm{~nm}$ and $3.4 \mathrm{~nm}$, respectively. The diameter of the particles of $\beta$-FeOOH estimated from this plot is comparable to that observed by TEM, although the diameter of the $\alpha$-FeOOH particles seems to be underestimated compared with the morphology observed by TEM. This suggests that the SAXS profile of the $\alpha$-FeOOH particles is reflected by their internal polycrystalline microstructure with some imperfections, even though it is not fully characterized here.

On the other hand, the effective thickness of thin tabular particles is evaluated using a thickness plot $\left(Q^{2} \times\right.$ $\left.\ln (I)-Q^{2}\right)$ [10]. The thickness plot of the SAXS profile for tabular particles of $\gamma$-FeOOH is shown in Fig. 5(b). The slope, $R_{t}^{2}$, in this plot is related to the thickness $t$ as $t=\sqrt{12} R_{t}$. From this relation, the thickness of the $\gamma-$ FeOOH particles is estimated to be about $2.9 \mathrm{~nm}$, which is comparable to that observed by TEM. As $\gamma-\mathrm{FeOOH}$ is a typical component of corrosion products of iron, this method may be useful for estimating the thickness of fine particles of $\gamma$-FeOOH formed under various conditions.

\section{B. Fine particles converted from $\mathrm{Fe}(\mathrm{OH})_{3}$ gel to $\beta$-FeOOH and $\alpha-\mathrm{Fe}_{2} \mathrm{O}_{3}$}

Fine particles of different ferric oxides that were sampled from the suspensions containing colloidal particles, which were obtained by aging condensed $\mathrm{Fe}(\mathrm{OH})_{3}$ gel, were also characterized using SAXS measurements. The condensed $\mathrm{Fe}(\mathrm{OH})_{3}$ gel are known to be converted to $\beta$ $\mathrm{FeOOH}$ and subsequently to $\alpha-\mathrm{Fe}_{2} \mathrm{O}_{3}$ by aging [3, 4], as $\mathrm{X}$-ray diffraction patterns of the fine particles are shown in Fig. 6. The crystallographic structure of fine particles of $\beta$-FeOOH intermediately formed during conversion may be, more or less, distorted, since X-ray diffraction peaks of reference particles of well-crystallized $\beta$-FeOOH are very sharp [19]. In addition, it is to be noted that the X-ray diffraction patterns shown in Fig. 6 may in- 

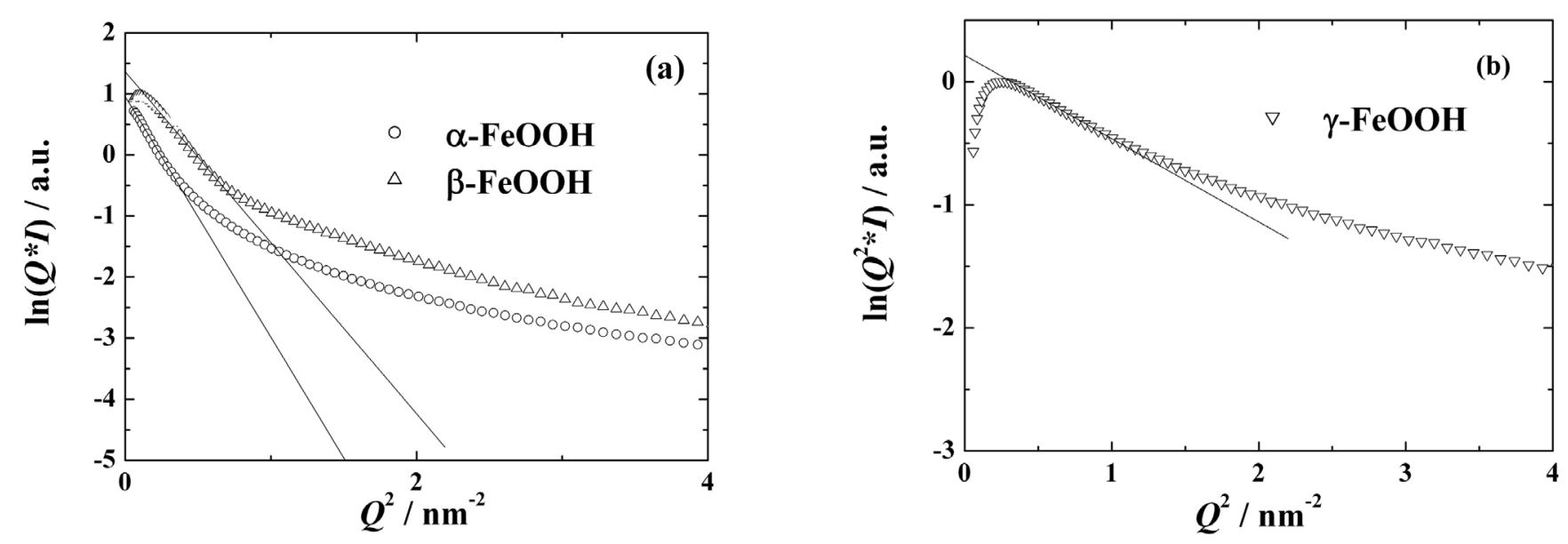

FIG. 5: (a) Cross-section plots of SAXS profiles of particles of $\alpha$-FeOOH and $\beta$-FeOOH, and (b) a thickness plot of a SAXS profile of particles of $\gamma$-FeOOH.

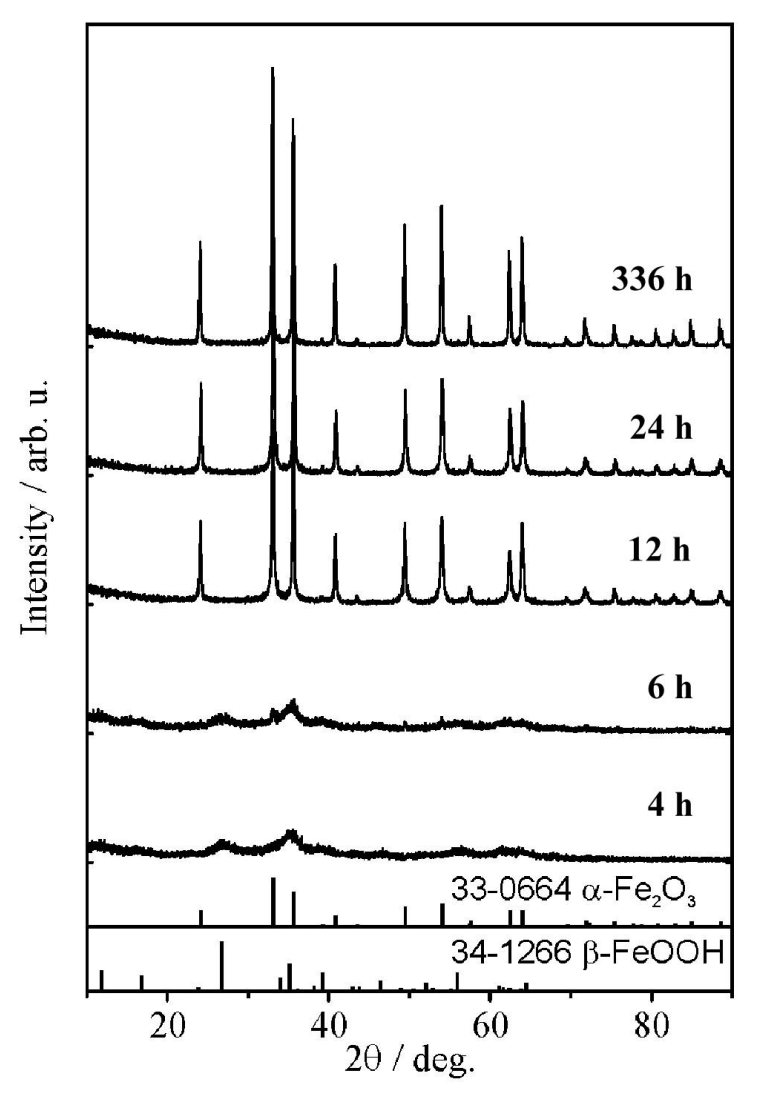

FIG. 6: X-ray diffraction patterns $\left(\mathrm{Cu} \mathrm{K}_{\alpha}\right)$ of fine particles extracted during the conversion process from $\mathrm{Fe}(\mathrm{OH})_{3}$ gel to $\beta-\mathrm{FeOOH}$ to $\alpha-\mathrm{Fe}_{2} \mathrm{O}_{3}$.

clude information not only of $\beta$-FeOOH particles, which are presumably poorly crystallized in aqueous media, but also of amorphous-like $\mathrm{Fe}(\mathrm{OH})_{3}$ gel, which does not exhibit a clear diffraction pattern.

Figure 7 shows SAXS profiles of fine particles extracted from suspensions formed by aging $\mathrm{Fe}(\mathrm{OH})_{3}$ gel at $373 \mathrm{~K}$ for $6,12,24$, and $336 \mathrm{~h}$. X-ray diffraction patters for these

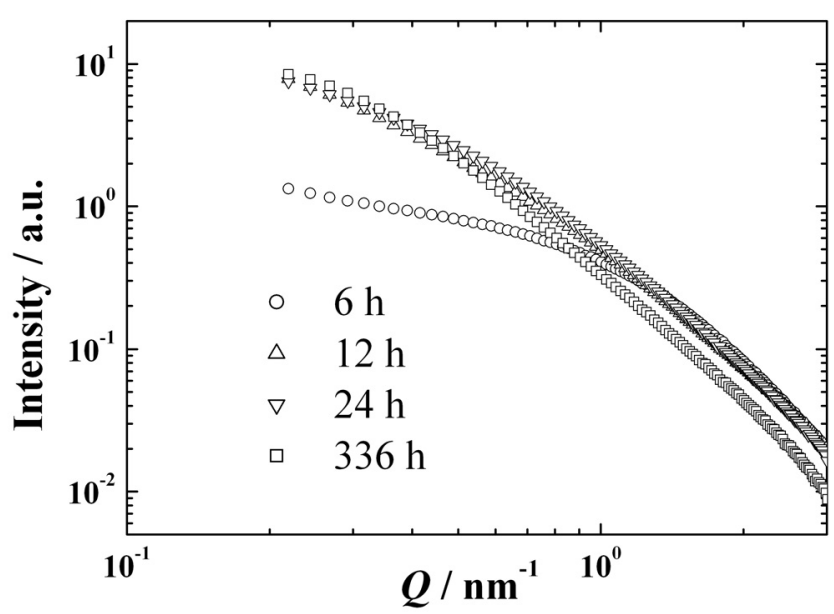

FIG. 7: SAXS profiles of fine particles extracted from the suspensions formed by aging $\mathrm{Fe}(\mathrm{OH})_{3}$ gel at $373 \mathrm{~K}$ for $6,12,24$, and $336 \mathrm{~h}$.

particles have shown that the gel was changed mainly to $\beta$-FeOOH by aging for $6 \mathrm{~h}$, and it is subsequently changed to $\alpha-\mathrm{Fe}_{2} \mathrm{O}_{3}$ by aging for $12 \mathrm{~h}$ at $373 \mathrm{~K}$. However, the SAXS profile of fine particles formed by aging for $6 \mathrm{~h}$ is not similar to that of reference particles of $\beta-\mathrm{FeOOH}$ shown in Fig. 4. This indicates that the morphology of fine particles of $\beta$-FeOOH formed by aging for $6 \mathrm{~h}$ is not simply acicular, and an amount of amorphous-like $\mathrm{Fe}(\mathrm{OH})_{3}$ gel still remains in the fine particles. In addition, intensities in a SAXS profile of fine particles formed by aging for 12 $\mathrm{h}$ or more are considerably higher than those for fine particles formed by aging for $6 \mathrm{~h}$ in the low scattering vector range. This is attributed to increases in the number density and size of fine particles by aging, which corresponds to the formation of $\alpha-\mathrm{Fe}_{2} \mathrm{O}_{3}$ particles by aging for long terms.

TEM micrographs of the fine particles sampled from the suspensions formed by aging $\mathrm{Fe}(\mathrm{OH})_{3}$ gel at $373 \mathrm{~K}$ for 6 , 12, and $336 \mathrm{~h}$ are shown in Figs. 8(a), (b), and (c), respec- 


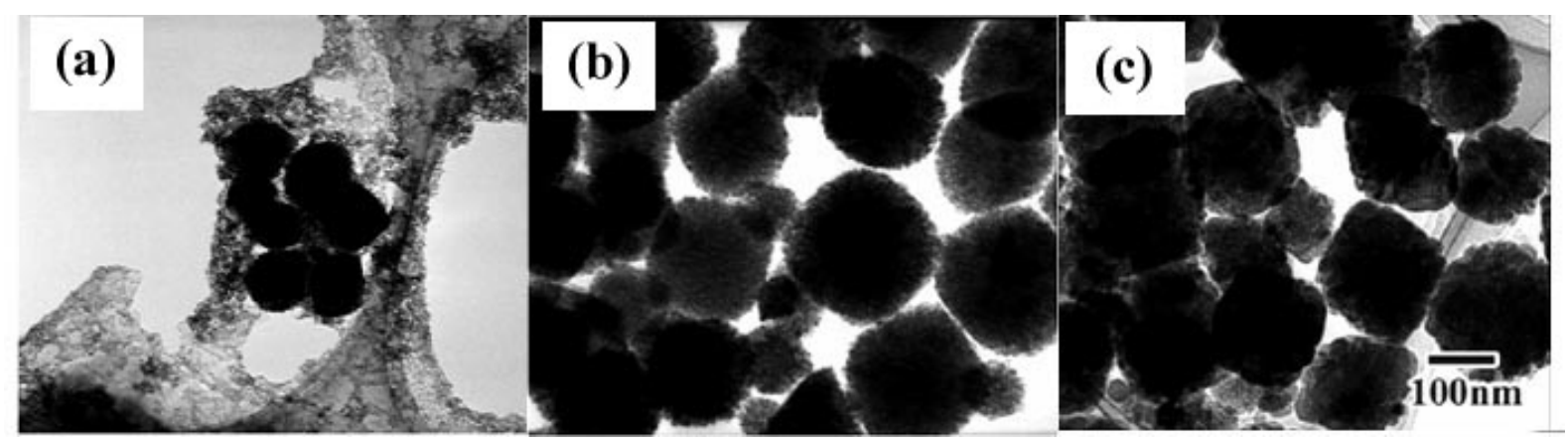

FIG. 8: Transmission electron micrographs of fine particles extracted from the suspensions formed by aging $\mathrm{Fe}(\mathrm{OH})_{3}$ gel at 373 $\mathrm{K}$ for (a) 6, (b) 12, and (c) $336 \mathrm{~h}$.

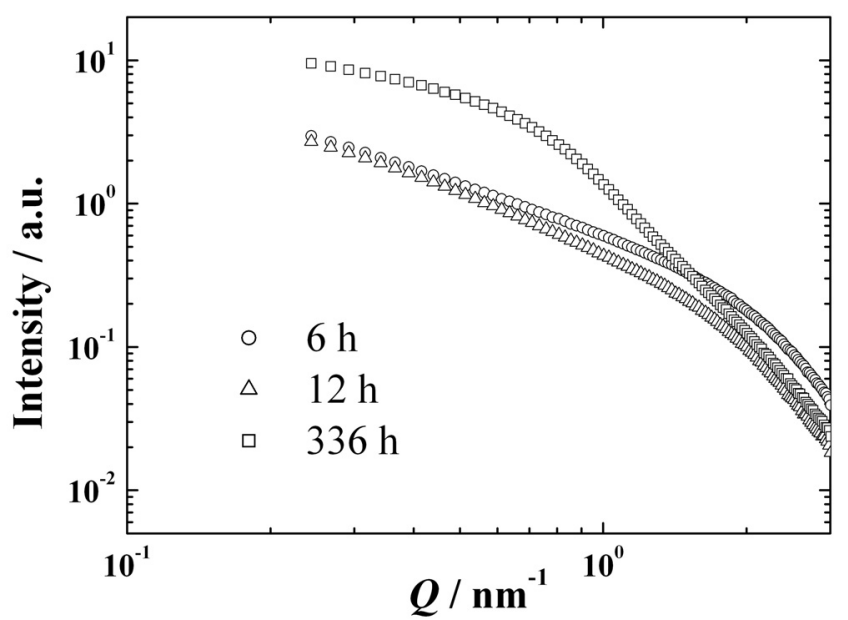

FIG. 9: SAXS profiles of fine particles extracted from the suspensions formed by aging $\mathrm{Fe}(\mathrm{OH})_{3}$ gel with $30 \%$ sulfate ions at $373 \mathrm{~K}$ for 6,12 , and $336 \mathrm{~h}$.

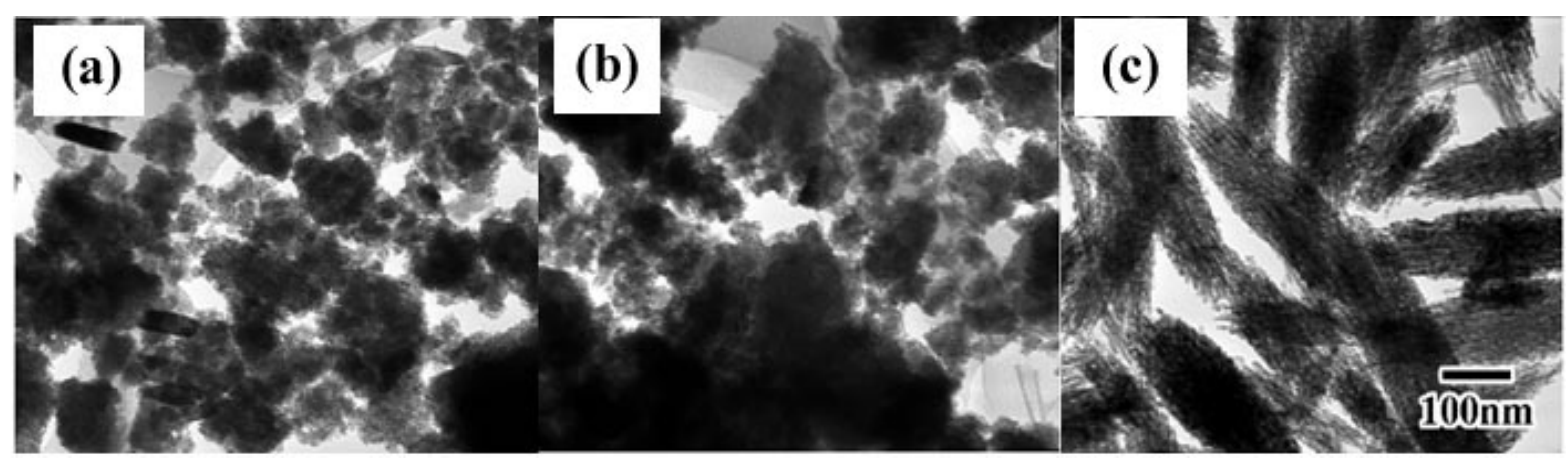

FIG. 10: Transmission electron micrographs of fine particles extracted from the suspensions formed by aging $\mathrm{Fe}(\mathrm{OH})_{3}$ gel with $30 \%$ sulfate ions at $373 \mathrm{~K}$ for (a) 6, (b) 12, and (c) $336 \mathrm{~h}$.

tively. It is to be noted that these micrographs are representatively taken in a selected area, and dark $\alpha-\mathrm{Fe}_{2} \mathrm{O}_{3}$ particles are emphasized in the images. The shape of the fine particles formed by aging for $6 \mathrm{~h}$, consisting mainly of $\beta-\mathrm{FeOOH}$, did not reveal acicular as compared with the reference particles of $\beta-\mathrm{FeOOH}$ as shown in Fig. 3(b). Nevertheless, these morphological changes of the fine particles correspond to the conversion process, in which the concentration of solutes and $\mathrm{pH}$ value in aqueous solution are changed [5]. The morphological results obtained by TEM appear to be correlated with the intensity changes in the SAXS profiles in the low scattering vector range.
Thus, the SAXS analysis may be a worthy method for characterizing entire conversion processes of these ferric oxides, even though the shapes of the fine particles formed in the processes are not simple $[5,6]$.

It is also of great interest to study the influence of sulfate or silicate ions on the conversion from $\mathrm{Fe}(\mathrm{OH})_{3}$ gel to $\beta$-FeOOH and $\alpha-\mathrm{Fe}_{2} \mathrm{O}_{3}$, since the conversion processes are influenced by foreign anions $[5,6]$ and the atomic-scale structure of $\beta$-FeOOH is known to be distorted by the addition of sulfate ions [18]. SAXS profiles of fine particles extracted from suspensions formed by aging $\mathrm{Fe}(\mathrm{OH})_{3}$ gel with $30 \%$ sulfate ions at $373 \mathrm{~K}$ for 6,12 , and $336 \mathrm{~h}$ are 


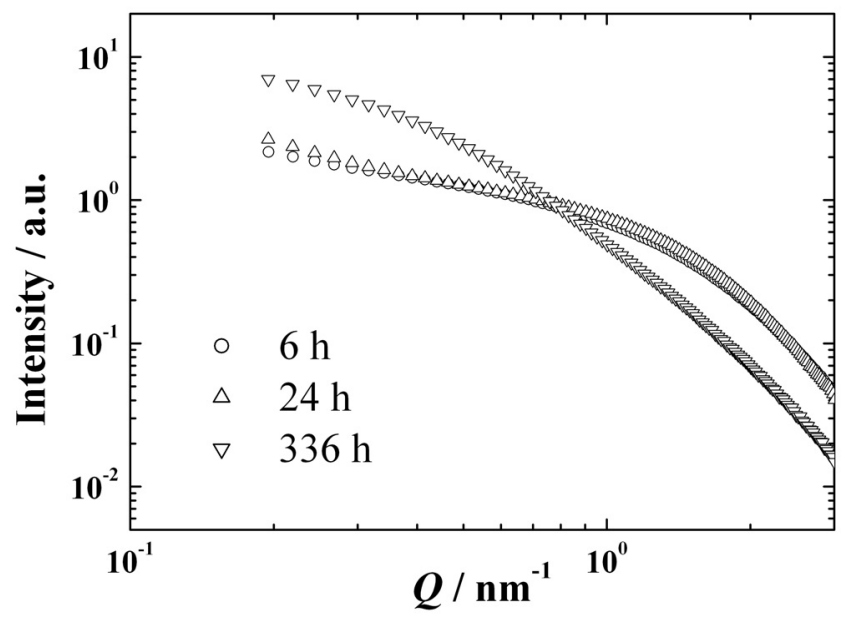

FIG. 11: SAXS profiles of fine particles extracted from the suspensions formed by aging $\mathrm{Fe}(\mathrm{OH})_{3}$ gel with $5 \%$ silicate ions at $373 \mathrm{~K}$ for 6,24 , and $336 \mathrm{~h}$.
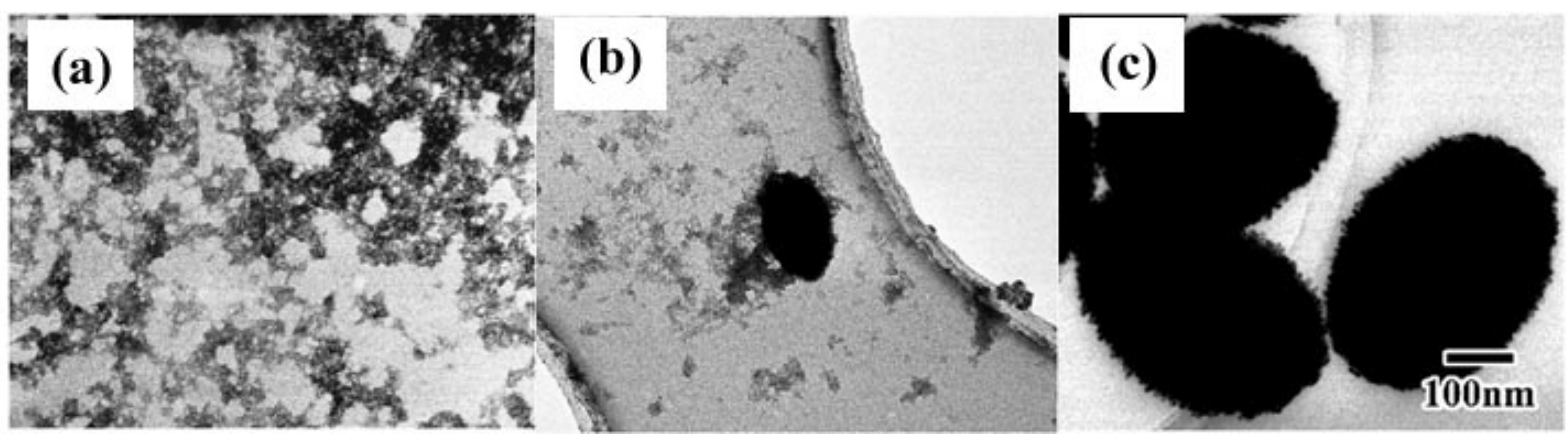

FIG. 12: Transmission electron micrographs of fine particles extracted from the suspensions formed by aging Fe(OH) 3 gel with $5 \%$ silicate ions at $373 \mathrm{~K}$ for (a) 6, (b) 24, and (c) $336 \mathrm{~h}$.

shown in Fig. 9. Intensities in the SAXS profiles in the low scattering vector range were increased in fine particles formed by aging for $336 \mathrm{~h}$, indicating that the formation of $\alpha-\mathrm{Fe}_{2} \mathrm{O}_{3}$ particles appears to be delayed by the addition of sulfate ions. TEM micrographs of fine particles extracted from the suspensions formed by aging $\mathrm{Fe}(\mathrm{OH})_{3}$ gel with sulfate ions at $373 \mathrm{~K}$ for 6,12 , and $336 \mathrm{~h}$ are shown in Figs. 10(a), (b), and (c), respectively. The morphology of fine particles formed by aging up to $12 \mathrm{~h}$, which are assigned primarily to $\beta-\mathrm{FeOOH}[5]$, is not acicular as well. On the other hand, the shape of fine particles of $\alpha-\mathrm{Fe}_{2} \mathrm{O}_{3}$, which were formed by long term aging, was changed from cubic to spindle-like by the addition of sulfate ions. Thus, these morphological results also seem to be correlated with the SAXS profiles shown in Fig. 9.

In a similar manner, the influence of silicate ions on the conversion of $\mathrm{Fe}(\mathrm{OH})_{3}$ gel was studied using SAXS measurements. Figure 11 shows SAXS profiles of fine particles extracted from suspensions formed by aging $\mathrm{Fe}(\mathrm{OH})_{3}$ gel with $5 \%$ silicate ions at $373 \mathrm{~K}$ for 6,24 , and $336 \mathrm{~h}$. The SAXS profiles of fine particles obtained by aging up to 24 $\mathrm{h}$ were changed by the addition of silicate ions, as compared to the results shown in Fig. 7. Typically, the intensities in the SAXS profiles of fine particles with $5 \%$ silicate ions aged at $373 \mathrm{~K}$ for 6 and $24 \mathrm{~h}$ were higher than those for fine particles without silicate ions in the high scattering vector range, while the intensities in the SAXS profiles of the fine particles with $5 \%$ silicate ions were lower in the low scattering vector range. These results indicate that the fine particles intermediately formed by aging, which were allocated mainly to $\beta$-FeOOH $[6]$, was kept very fine by the addition of silicate ions. TEM micrographs of fine particles aged for 6,24 , and $336 \mathrm{~h}$ are shown in Figs. 12 (a), (b), and (c), respectively. Fine particles of $\alpha-\mathrm{Fe}_{2} \mathrm{O}_{3}$ with dark contrast were observed in samples aged for 336 $\mathrm{h}$, and the shape of the converted $\alpha-\mathrm{Fe}_{2} \mathrm{O}_{3}$ particles was relatively large and ellipsoidal. These results suggest that the conversion of $\mathrm{Fe}(\mathrm{OH})_{3}$ gel was suppressed by the addition of silicate ions, which is presumably due to the adsorption of silicate ions on the particle surface of these ferric oxides. These results seem to be consistent with the SAXS profiles of fine particles added with silicate ions, as shown in Fig. 11.

In general, if fine particles are nearly mono-dispersive, their SAXS profile in the low scattering vector range provides information on the size or gyration radius, the correlated distribution and so on of the fine particles, whereas the surface structure of the particles is discussed using fractal dimension in the large scattering vector range. By combining the analysis of the SAXS profile with microstructural observation, the morphology of fine particles, which are even poorly crystallized, may be further characterized. In this work, SAXS measurements were used for characterizing reference particles of relatively well-crystallized ferric oxyhydroxides, and ferric oxides which were converted from $\mathrm{Fe}(\mathrm{OH})_{3}$ gel to $\beta$-FeOOH and 
$\alpha-\mathrm{Fe}_{2} \mathrm{O}_{3}$. Since these fine particles appear to be far from mono-dispersive, precise analysis of the morphology by SAXS profiles is not simple. Nevertheless, SAXS profiles are shown to correspond to the conversion process of the $\mathrm{Fe}(\mathrm{OH})_{3}$ gel to $\beta$-FeOOH and $\alpha-\mathrm{Fe}_{2} \mathrm{O}_{3}$, of which the entire change was not necessarily evaluated in observation of selected area by TEM. Thus, the combination of SAXS measurements with TEM observation and X-ray diffraction measurement may be informative in the characterization of fine particles, such as poorly crystallized iron oxides formed by aging in aqueous media. Furthermore, the nano-scale heterogeneity around specific elements in fine particles may be obtained by SAXS measurements coupled with anomalous scattering using synchrotron radiation. The local structure obtained by extended X-ray absorption fine structure (EXAFS) of fine particles is also useful in discussing the formation mechanism of fine particles from ferric and/or ferrous ions dissolved in aqueous media, and such experiments are in progress.

\section{CONCLUSIONS}

SAXS measurement, for which the system was designed for a beamline of synchrotron radiation, and TEM observation were carried out for characterizing the fine particles of different ferric oxides including hydroxides and oxyhydroxides. SAXS profiles of the reference particles of $\beta$-FeOOH and $\beta$-FeOOH fundamentally corresponded to their morphologies observed by TEM, while a SXAS profile of reference particles of $\alpha-\mathrm{FeOOH}$ appears to be influenced by the internal microstructure in the particles. SAXS profiles of different fine particles formed from $\mathrm{Fe}(\mathrm{OH})_{3}$ gel appear to be correlated with the conversion processes of the $\mathrm{Fe}(\mathrm{OH})_{3}$ gel to $\beta$ - $\mathrm{FeOOH}$ and $\alpha-\mathrm{Fe}_{2} \mathrm{O}_{3}$, although the morphology of the fine particles intermediately formed during conversion was not sufficiently consistent with that of the reference particles. The SAXS profiles also indicated that foreign anions such as sulfate and silicate ions suppressed the conversion processes. Thus, the combination of SAXS measurement with TEM observation and X-ray diffraction measurement is considered to be useful for characterizing fine particles with complicated morphology and composition, consisting of different metallic oxides formed in aqueous media.

\section{Acknowledgments}

The authors would like to express their sincere thanks to Mr. S. Tanaka for his help in the design of the SAXS system and to Mr. N. Yagi for his help in the operation of BL15XU, SPring-8. The synchrotron radiation experiments were performed at SPring- 8 with the approval of the National Institute for Materials Science as part of the Nanotechnology Support Project of the Ministry of Education, Culture, Sports, Science and Technology (Proposal No. 2004A0066, 2004B00090/BL15XU). This study is supported by a Grant-in-Aid for the Scientific Research Fund from the Japan Society for the Promotion of Science (No. 17206075).
[1] R. M. Cornell, and U. Schwertmann, The Iron Oxides, (John-Wiley VCH, Weinheim, 2003).

[2] J.-P. Jolivet, M. Henry, J. Livage, and E. Bescher, Metal Oxide Chemistry and Synthesis, (John-Wiley \& Sons, Chichester, 2000).

[3] T. Sugimoto, Fine particles: Synthesis, Characterization, and Mechanisms of Growth, (Marcel Dekker, New York, 2000).

[4] T. Sugimoto, Y. Wang, H. Itoh, and A. Muramatsu, Colloids Surf. A 134, 265 (1998).

[5] K. Kanie, A. Muramatsu, S. Suzuki, and Y. Waseda, Mater. Trans. 45, 968 (2004).

[6] S. K. Kwon, K. Kimijima, K. Kanie, A. Muramatsu, S. Suzuki, E. Matsubara, and Y. Waseda, ISIJ Inter. 42, 77 (2005).

[7] S. K. Kwon, K. Kimijima, K. Kanie, A. Muramatsu, S. Suzuki, E. Matsubara, and Y. Waseda, Mater. Trans. 46 , 155 (2005).

[8] T. Ishikawa, H. Nakazaki, A. Yasukawa, K. Kandori, and M. Seto, Corros. Sci. 41, 1665 (1999).

[9] T. Ishikawa, T. Motoki, R. Katoh, A. Yasukawa, K. Kandori, T. Nakayama, F. Yuse, J. Colloid Interface Sci. 250, 74 (2002).
[10] O. Kratky, and O. Glatter, Small-Angle X-Ray Scattering, (Academic Press, New York, 1982).

[11] H. Brumberger, Modern Aspects of Small-Angle Scattering, (Kluwer Academic Publishers, New York, 1995).

[12] H. Okuda, S. Ochiai, K. Ito, and Y. Amemiya, Scripta Mater. a 46, 795 (2002).

[13] X. Y. Xiong, M. Ohnuma, T. Ohkubo, D. H. Ping, K. Hono, S. Ohnuma, H. Fujimori, and T. Masumoto, J. Mag. Magnetic Mater. 265, 83 (2003).

[14] F. Meneau, G. Sankar, N. Morgante, S. Cristol, C. R. A. Catlow, J. M. Thomas, and G. N. Greaves, Nucl. Inst. Methods in Phys. Res. Sec. B 199, 499 (2003).

[15] Y. Waseda, Anomalous X-Ray Scattering for Materials Characterization, (Springer -Verlag, Heidelberg, 2002).

[16] M. J. Regan, and A. Bienenstock, J. Non-Crystalline Solids 192, 644 (1995).

[17] J. Zhang, L. X. Rong, Y. Liu, and B. Z. Dong, Mater. Sci. Eng. A351, 224 (2003).

[18] S. K. Kwon, S. Suzuki, M. Saito, T. Kamimura, H. Miyuki and Y. Waseda, Mater. Trans. 46, 2030 (2005).

[19] S. K. Kwon, S. Suzuki, M. Saito and Y. Waseda, Corros. Sci. 47, 2543 (2005). 